\title{
The Prognostic and Predictive Role of Somatic BRCA Mutations in Ovarian Cancer: Results from a Multicenter Cohort Study
}

\author{
Angela Toss ${ }^{1,2}{ }^{\oplus}$, Claudia Piombino ${ }^{1}$, Elena Tenedini ${ }^{3}\left(\mathbb{D}\right.$, Alessandra Bologna ${ }^{4}$, Elisa Gasparini ${ }^{4}$, \\ Vittoria Tarantino ${ }^{5}$, Maria Elisabetta Filieri ${ }^{6}$, Luca Cottafavi ${ }^{7}$, Filippo Giovanardi ${ }^{8} \mathbb{D}$, Stefano Madrigali ${ }^{8}$, \\ Monica Civallero ${ }^{2}$, Luigi Marcheselli ${ }^{9}$, Isabella Marchi ${ }^{1}$, Federica Domati ${ }^{1}$, Marta Venturelli ${ }^{1}{ }^{\mathbb{D}}$, Elena Barbieri ${ }^{1}$, \\ Giovanni Grandi ${ }^{10}\left(\mathbb{D}\right.$, Enrico Tagliafico ${ }^{3,11,12}$ (D) and Laura Cortesi ${ }^{1, *(\mathbb{D})}$
}

1 Department of Oncology and Hematology, Azienda Ospedaliero Universitaria di Modena, 41124 Modena, Italy; angela.toss@unimore.it (A.T.); claudia.piombino@outlook.com (C.P.); marchi.isabella@policlinico.mo.it (I.M.); fdomati@unimore.it (F.D.); martaventurelli@msn.com (M.V.); barbieri.elena@aou.mo.it (E.B.)

2 Department of Surgery, Medicine, Dentistry and Morphological Sciences with Transplant Surgery, Oncology and Regenerative Medicine Relevance, University of Modena and Reggio Emilia, 41124 Modena, Italy; monica.civallero@unimore.it

3 Department of Medical and Surgical Sciences, University of Modena and Reggio Emilia, 41124 Modena, Italy; tenedini.elena@gmail.com (E.T.); enrico.tagliafico@unimore.it (E.T.)

4 Department of Oncology, Arcispedale S. Maria Nuova IRCCS, 42123 Reggio Emilia, Italy; bologna.alessandra@ausl.re.it (A.B.); gaspariniel@ausl.re.it (E.G.)

5 PhD Program in Clinical and Experimental Medicine, University of Modena and Reggio Emilia, 41124 Modena, Italy; vittoriatarantino@hotmail.it

6 ASL Lecce, Polo Oncologico "Vito Fazzi", 73100 Lecce, Italy; melisabe.filieri@libero.it

7 Oncology Unit, Azienda Unità Sanitaria Locale di Modena, Ramazzini Hospital, 41012 Carpi, Italy; lu.cottafavi@ausl.mo.it

check for

updates

Citation: Toss, A.; Piombino, C.; Tenedini, E.; Bologna, A.; Gasparini,

E.; Tarantino, V.; Filieri, M.E.;

Cottafavi, L.; Giovanardi, F.; Madrigali, S.; et al. The Prognostic and Predictive Role of Somatic $B R C A$ Mutations in Ovarian Cancer: Results from a Multicenter Cohort Study. Diagnostics 2021, 11, 565. https:// doi.org/10.3390/diagnostics11030565

Received: 26 February 2021

Accepted: 18 March 2021

Published: 21 March 2021

Publisher's Note: MDPI stays neutral with regard to jurisdictional claims in published maps and institutional affiliations.

Copyright: (๑) 2021 by the authors. Licensee MDPI, Basel, Switzerland. This article is an open access article distributed under the terms and conditions of the Creative Commons Attribution (CC BY) license (https:// creativecommons.org/licenses/by/ $4.0 /)$.
8 Medical Oncology Unit, Azienda Unità Sanitaria Locale, IRCCS di Reggio Emilia, 42122 Reggio Emilia, Italy; giovanardifilippo@gmail.com (F.G.); stefano.madrigali@ausl.re.it (S.M.)

9 Fondazione Italiana Linfomi (FIL), Department of Oncology and Hematology, Azienda Ospedaliero Universitaria di Modena, 41124 Modena, Italy; Imarcheselli@unimore.it

10 Department of Obstetrics, Gynecology and Pediatrics, Obstetrics and Gynecology Unit, Azienda Ospedaliero Universitaria di Modena, 41124 Modena, Italy; giovanni.grandi@unimore.it

11 Department of Laboratory Medicine and Pathology, Diagnostic Hematology and Clinical Genomics Unit, Azienda Ospedaliero Universitaria di Modena, 41124 Modena, Italy

12 Center for Genome Research University of Modena and Reggio Emilia, 41124 Modena, Italy

* Correspondence: hbc@unimore.it

Abstract: Previous research involving epithelial ovarian cancer patients showed that, compared to germline $B R C A$ (gBRCA) mutations, somatic BRCA (sBRCA) mutations present a similar positive impact with regard to overall survival (OS) and platinum and PARP (poly (ADP-ribose) polymerase) inhibitor sensitivity. Nevertheless, molecular testing in these studies did not include copy number variation $(\mathrm{CNV})$ analyses of $B R C A$ genes. The aim of this study was to explore the prognostic and predictive role of sBRCA mutations as compared to gBRCA mutations in patients who were also tested for CNVs. Among the 158 patients included in the study, 17.09\% of patients carried a pathogenic or likely pathogenic gBRCA variant and $15.19 \%$ of patients presented pathogenetic or likely pathogenic sBRCA variants and/or CNVs. Overall, $81.6 \%$ of the patients included in this study were diagnosed with a serous histotype, and $77.2 \%$ were in advanced stages. Among women diagnosed in advanced stages, gBRCA patients showed better progression-free survival and OS as compared to sBRCA and wild-type patients, whereas sBRCA patients did not show any advantage in outcome as compared to wild-type patients. In this study, the introduction of CNV analyses increased the detection rate of sBRCA mutations, and the resulting classification among gBRCA, sBRCA and wild-type patients was able to properly stratify the prognosis of OC patients. Particularly, sBRCA mutation patients failed to show any outcome advantage as compared to wild-type patients.

Keywords: BRCA; ovarian cancer; copy number variation; genetic testing 


\section{Introduction}

More than one-fifth of invasive epithelial ovarian cancers present hereditary susceptibility. In about $65-85 \%$ of those cases, the genetic defect is a germline that is likely pathogenic or a pathogenic variant in one of the $B R C A$ genes [1]. In particular, these germline $B R C A$ (gBRCA) variants occur in $4-14 \%$ of all women with unselected ovarian cancers (OCs) regardless of family history, in $5-18 \%$ of serous OCs, and in about $22 \%$ of high-grade serous OC cases [2-8]. Interestingly, ovarian cancers developed by gBRCA mutation carriers present peculiar clinical and histopathological features: an increased likelihood of a high-grade serous histotype, sensitivity to platinum agents and PARP (poly (ADP-ribose) polymerase) inhibitors, and longer median overall survival (OS) [9-15]. Besides $B R C A 1$ and $B R C A 2$ genes, several other suppressor genes and oncogenes have been associated with hereditary OC, including mismatch repair (MMR) genes, TP53, and several genes involved in the double-strand break repair system such as ATM, CHEK2, RAD51C, RAD51D, BRIP1, and PALB2 [1]. BRCA-negative tumors with a defect in the homologous recombination system express the BRCAness profile, a specific phenotype with features and behaviors similar to those of BRCA-related cancers [16]. In particular, as already shown by several clinical trials, these patients may benefit from treatment with PARP inhibitors. So far, however, validated tests for the identification of BRCAness tumors are still needed [17].

In sporadic OCs, alterations of $B R C A 1$ and $B R C A 2$ genes may also occur through somatic mutations or epigenetic silencing. In contrast to germline mutation analysis, somatic $B R C A$ testing is routinely performed using next-generation sequencing (NGS), due to the better sensitivity for analyzing tumor tissue DNA as compared to Sanger methodology. In previous studies, somatic BRCA (sBRCA) mutations have globally been reported in approximately $5-7 \%$ of ovarian cancer cases [17-22]. While the prognostic and predictive roles of gBRCA mutations have been largely demonstrated and shared, it is not entirely clear whether harboring a sBRCA mutation brings the same prognostic and predictive advantages. The reasons for this uncertainty are also related to challenges in somatic mutation testing, ranging from the need for high-quality tissue selection and DNA isolation to correct variant interpretation. Moreover, somatic mutations in patients may change over time and according to the site of tumor evaluation, and as a consequence of treatment, cancer evolution, and resistance development [23].

A few small cohort studies have previously shown that, like gBRCA, pathogenic sBRCA variants have a similar positive impact on OS as well as platinum and PARP inhibitor sensitivity $[3,24-26]$. On the other hand, a more recent study found no significant impact of sBRCA mutations on progression-free survival (PFS) or OS [27]. Nevertheless, all these studies suffered from relevant shortcomings, particularly in terms of the copy number variation (CNV) analysis of $B R C A$ genes.

For the purpose of exploring the prognostic and predictive role of sBRCA mutations as compared to gBRCA mutations and wild-type $B R C A$, clinical pathological characteristics and survival outcomes were evaluated in 158 Italian OC patients. Patients in the study underwent both germline and somatic $B R C A$ genetic testing with an NGS amplicon-based approach for tumor samples, specifically designed with shorter amplicons to generate high-quality data for formalin-fixed paraffin-embedded (FFPE) samples.

\section{Materials and Methods}

\subsection{Study Population and Design}

Since 1995, the Modena Family Cancer Clinic (MFCC), which is located in the Emilia Romagna region (Northern Italy), has offered genetic counseling to individuals with a personal or family history of breast cancer (BC) and/or OC in accordance with the criteria recommended by the Emilia Romagna region for $B R C A$ genetic testing and the Italian Association of Medical Oncology (AIOM) Guidelines [28,29] (Table 1). The Regional and National indications act on the backdrop of results from Study 19 [30], Study 42 [31], and the SOLO2 studies [32], as well as the Food and Drug Administration (FDA) and the 
European Medicines Agency (EMA) approval of olaparib for the maintenance treatment of patients with platinum-sensitive relapsed $B R C A$-mutated (germline or somatic) epithelial OC responding to platinum-based chemotherapy. Thus, at the beginning of 2017 the MFCC started to provide somatic and germline $B R C A$ genetic testing for patients diagnosed with high-grade serous OC, and in 2018, somatic and germline BRCA genetic testing was extended to all patients with non-mucinous and non-borderline epithelial OCs.

Table 1. The Modena Family Cancer Clinic (MFCC) criteria for genetic testing in BC and OC patients. $\mathrm{BC}$ : breast Cancer; OC: ovarian cancer.

\begin{tabular}{c}
\hline BC and OC in the Same Patient or Family \\
\hline $\begin{array}{c}\text { OC, fallopian tube, or primary peritoneal cancer (mucinous and } \\
\text { borderline types excluded) at any age }\end{array}$ \\
\hline Male BC \\
Triple-negative BC diagnosed at $\leq 60$ years \\
BC diagnosed at $\leq 35$ years \\
\hline At least 2 first-degree blood relatives with BC with at least 1 diagnosed $\leq 40$ years or \\
with a bilateral presentation in the same family
\end{tabular}

During pre-test counseling, information on the family and personal history of cancer is collected, and a family pedigree is drawn up, including third-degree relatives on both the maternal and paternal sides. Healthy women with a family history of BC and/or OC are referred to the MFCC by their general practitioners or the radiologists who perform population-based screening mammography after a preliminary investigation that is required to reach a minimum cut-off point according to specific criteria. On the other hand, $\mathrm{BC}$ and $\mathrm{OC}$ patients are referred to the MFCC by their oncologists, radiologists, surgeons, or gynecologists. Individuals who meet the criteria can undergo genetic testing; then, in case of a positive result, the search for a specific pathogenic or likely pathogenic variant can be offered to other family members.

For the purpose of our study, the first consecutive OC patients undergoing somatic and germline BRCA testing at the MFCC between January 2017 and December 2018 (in accordance with the testing criteria described above) were included into the study regardless of tumor histotype or stage at diagnosis. The patients were referred to the MFCC from five oncology units in the two provinces of Modena and Reggio Emilia. All of them underwent molecular testing at the same laboratory. The patients were then stratified according to whether they were gBRCA mutation carriers (patients carrying a likely pathogenic or pathogenic $B R C A$ variant in both somatic and germline samples, with or without other likely pathogenic or pathogenic sBRCA variants), sBRCA mutation carriers (patients carrying a likely pathogenic or pathogenic variant in a tumor sample but not in the germline counterpart), and wild-type patients (wtBRCA, patients carrying no likely pathogenic or pathogenic sBRCA or gBRCA variant). OS, PFS, and time from diagnosis to second disease progression or death from any cause (PFS2) were evaluated in each group. Finally, in order to assess the possible differences in outcome between somatic single nucleotide variants (SNVs)/deletions (indels) and CNVs, sBRCA patients were then divided into two subgroups: patients with somatic SNVs/indels (s1BRCA) and those with somatic CNVs (s2BRCA). Patients with both SNVs/indel and CNVs were included in the s1BRCA group.

\subsection{BRCA Somatic Testing and Variant Interpretation}

Somatic analyses were carried out on formalin-fixed paraffin-embedded (FFPE) specimens from either primary carcinomas or related metastases, prepared following the College of American Pathologist Guidelines [33]. In 40 cases, tissues came from core biopsies, whereas 118 samples were surgical specimens of the primary tumor. Appropriate tissue samples were eventually macrodissected to enrich tumor content, and the DNA was isolated from selected areas with neoplastic cell content $>50 \%$. An automated specific DNA 
extraction protocol was adopted (Maxwell@16 FFPE Tissue LEV DNA Purification Kit, Promega, Madison, Wisconsin, USA) and fluorometric quantification was undertaken to assess the exact amount of double stranded DNA (dsDNA) (Qubit dsDNA High Sensitivity, Thermo Scientific, Waltham, Massachusetts, USA). All the 158 samples showed a sufficient quantity of extracted DNA to continue the analysis. Amplicon-based library setup and sequencing were performed via a totally automated $B R C A 1$ and $B R C A 2$ Oncomine protocol with the IonChef and IONS5 platforms (Thermo Scientific), starting from a minimum of 15 nanograms of DNA per sample. The Oncomine panel covers complete coding sequences and intron-exon junctions of $B R C A 1$ and $B R C A 2$ genes (amounting to 265 amplicons and 64-bp exon padding). Sequencing depth was set according to the percentage of tumor cells in the samples under analysis in order to reach a minimum variant coverage of 50 times and detect a minimum variant allele frequency (VAF) as low as $5 \%$.

Data were analyzed for either single nucleotide variants (SNVs), small insertions, or deletions (indels) through a proprietary Ion Reporter analysis workflow with parameters for somatic DNA samples, personalized with a hot-spot file calling for the presence or absence of all of the likely pathogenic or pathogenic $B R C A 1$ and $B R C A 2$ variants annotated in Clinvar, LOVD, ENIGMA, and internal private databases at the moment of sequencing.

Moreover, data were analyzed for CNVs through the Ion Reporter analysis workflow using a proprietary algorithm named the Variability Correction Informatics Baseline (VCIB) that uses an informatics baseline created with 75 diverse samples (with no BRCA1/2 CNVs) to allow the assessment of corrected $\log 2$ ratios of amplicons of identified CNV regions in input sample data. This was followed by a correction for the percent tumor cellularity recorded for the sample to give copy number and confidence interval data for the identified $\mathrm{CNV}$ regions. Both algorithms employed to compute the corrected $\log 2$ ratios and the correction for the tumor fraction are proprietary.

Moreover, genetic variant annotations were integrated with open-source bioinformatics tools customized and internally validated (Annovar [34] and Variant Effect Predictor [35]). The annotations were then reported using the international standard Human Genome Variation Society (HGVS) nomenclature and classification into five classes according to the American College of Medical Genetics and Genomics (ACMG criteria) [36].

Every likely pathogenic (C4) or pathogenic (C5) SNV or indel found via NGS in the somatic sample was confirmed by Sanger sequencing in both somatic and germline DNA patient samples. Germline DNA was isolated with an automated method implemented on the QIAsymphony platform (Qiagen, Germantown, Maryland, USA) starting from $300 \mu \mathrm{L}$ of peripheral blood samples collected in EDTA tubes; the quantity and quality of nucleic acids were checked using a Qubit dsDNA High Sensitivity kit and Nanodrop (Thermo Scientific). Sanger sequencing was performed with predesigned Invitrogen M13 forward and reverse primers and the BigDye ${ }^{\mathrm{TM}}$ Direct Cycle Sequencing Kit, sequenced with the Applied Biosystems ${ }^{\circledR 3500 x L}$ Dx Genetic Analyzer platform and analyzed with Minor Variant Finder or SeqScape3 software (ThermoFisher Scientific).

The CNVs found in the somatic samples could not be confirmed with an alternative method in the somatic samples, but their presence/absence was ascertained in the matched germline sample via the Multiple Ligation Probe Amplification method (MLPA, MRC Holland, Amsterdam, The Netherlands), performed with the Applied Biosystems ${ }^{\circledR 3500 x L}$ Dx Genetic platform and analyzed with Coffalyser.Net (MRC Holland) software updated to the latest available version.

\subsection{Statistical Analysis}

Data were analyzed using Fisher's exact test to identify associations between categorical variables. Two-tailed $p$ values of $<0.05$ were considered statistically significant. OS was measured from the date of diagnosis until death from any cause or date of last known contact for living patients. PFS was defined as the date of diagnosis to progressive disease or death from any cause, whereas PFS2 was defined as the time from diagnosis to second disease progression or death from any cause. The OS, PFS, and PFS2 distributions were 
calculated using the Kaplan-Meier method and time-to-event distributions were compared using the log-rank test (univariate regression). The Cox regression model was used to estimate the hazard ratio of factors included in multivariable analyses. Statistical analyses were performed using Stata version 14.2 (StataCorp. LLC, College Station, TX, USA), and SPSS v20.0 (IBM Corp., Armonk, NY, USA).

\section{Results}

\subsection{Patient Characteristics}

Patient characteristics are reported in Table 2. One-hundred-fifty-eight patients were included in the analyses. A total of 27 (17.09\%) patients carried a pathogenetic gBRCA mutation: $18(66.7 \%)$ in BRCA1 and $9(33.3 \%)$ in BRCA2. Moreover, $24(15.19 \%)$ patients presented an sBRCA mutation: 10 (41.7\%) in BRCA1, $13(54.2 \%)$ in BRCA2, and 1 (4.2\%) in both the BRCA1 and BRCA2 genes. Finally, 107 (67.72\%) patients presented no mutations. The patients carrying a gBRCA or sBRCA mutation were significantly younger (respectively 58 and 56 years) than the wild-type patients (70 years) $(p=0.04)$. The International Federation of Gynecology and Obstetrics (FIGO) stage at diagnosis was advanced (stage IIIIV) in $78.2 \%$ of cases, with no significant difference among subgroups $(p>0.05)$. The most frequent histotype was serous for all subgroups (92.6\% in gBRCA, 79.2\% in sBRCA, 79.4\% in wtBRCA) $(p>0.05)$. Although not statistically significant in this sample, gBRCA mutation carriers were more likely to present a BC and/or OC family history, to be diagnosed at advanced stages (85.2\%), and to have a serous histotype (92.6\%) as compared to sBRCA and wtBRCA patients. While $61.7 \%$ of wtBRCA carriers, $59.3 \%$ of gBRCA mutation carriers, and $79.2 \%$ of sBRCA mutation carriers underwent surgery upfront $(p>0.05), 18.5 \%$ of gBRCA patients underwent neoadjuvant chemotherapy, as compared to $15.9 \%$ of wtBRCA and $0 \%$ of sBRCA patients $(p=0.05)$. Besides, $24.7 \%$ of wtBRCA patients, $19.2 \%$ of gBRCA mutation carriers, and $26.1 \%$ of sBRCA mutation carriers presented macroscopic residual disease after surgery $(p>0.05)$. All patients underwent platinum-based first-line treatment, except one of the sBRCA $(4.2 \%)$ carriers, who did not receive any systemic treatment.

\subsection{Outcome Analysis}

Outcome analyses were conducted with 157 patients since for one patient the data regarding treatment were not available. Overall, after a median follow-up of 45.7 months, the median PFS was observed to be 18 months in wild-type patients, 41 months in gBRCA carriers, and 31 months sBRCA mutation carriers (log rank = 0.109) (Figure 1a). No patient received PARP inhibitors as maintenance after first-line therapy. Median progression-free survival 2 (PFS2) was 24 months in wild-type patients, not obtained in gBRCA carriers, and was 40 months for sBRCA mutation carriers (log rank $=0.003$ ) (Figure 1b). Three sBRCA (12.5\%) and six gBRCA (22.2\%) mutation carriers received a PARP inhibitor as maintenance after second-line therapy (eight patients received olaparib and one patient niraparib). Median OS was 72 months in wild-type patients, and not obtained in gBRCA carriers and sBRCA mutation carriers (log rank =0.038) (Figure 1c). sBRCA carriers did not show any advantage in terms of PFS (log rank $=0.15$, Figure $1 \mathrm{a})$, PFS2 (log rank $=0.22$, Figure $1 b)$, and OS (log rank $=0.47$, Figure 1c) as compared to wild-type patients. Finally, PFS, PFS2, and OS did not significantly differ between s1BRCA and s2BRCA patients $(\log$ rank $=0.34$, Figure $1 d ; \log$ rank $=0.48$, Figure 1e; log rank =0.21, Figure 1f). 
Table 2. Patient and tumor characteristics by $B R C A$ mutational status. wtBRCA: wild-type BRCA; gBRCA: germline $B R C A$; sBRCA: somatic BRCA; SD: standard deviation; FIGO: International Federation of Gynecology and Obstetrics.

\begin{tabular}{|c|c|c|c|c|c|c|c|}
\hline & $\begin{array}{c}\text { wtBRCA } \\
(n=107,67.7 \%)\end{array}$ & & $\begin{array}{c}\text { gBRCA } \\
(n=27,17.1 \%)\end{array}$ & & $\begin{array}{c}\text { sBRCA } \\
(n=24,15.2 \%)\end{array}$ & & $p$ Value \\
\hline Median age (SD) & $70.50(0.71)$ & & $58.50(19.09)$ & & $56.00(16.97)$ & & 0.04 \\
\hline & $\mathrm{n}$ & $\%$ & $\mathrm{n}$ & $\%$ & $\mathrm{n}$ & $\%$ & \\
\hline Family history of $\mathrm{BC}^{1}$ & 38 & 35.51 & 14 & 51.85 & 9 & 37.50 & $>0.05$ \\
\hline Family history of $\mathrm{OC}^{1}$ & 7 & 6.54 & 6 & 22.22 & 4 & 16.67 & $>0.05$ \\
\hline $\begin{array}{c}\text { Family history of } \\
\mathrm{BC}+\mathrm{OC}{ }^{1}\end{array}$ & 2 & 1.87 & 4 & 14.81 & 1 & 4.17 & $>0.05$ \\
\hline $\begin{array}{c}\text { FIGO stage } \\
\text { I } \\
\text { II } \\
\text { Total I-II } \\
\text { III } \\
\text { IV } \\
\text { Total III-IV } \\
\text { Unknown }\end{array}$ & $\begin{array}{c}11 \\
12 \\
23 \\
50 \\
33 \\
83 \\
1\end{array}$ & $\begin{array}{c}10.28 \\
11.21 \\
21.50 \\
46.73 \\
30.84 \\
77.57 \\
0.93\end{array}$ & $\begin{array}{c}2 \\
1 \\
3 \\
18 \\
5 \\
23 \\
1\end{array}$ & $\begin{array}{c}7.41 \\
3.70 \\
11.11 \\
66.67 \\
18.52 \\
85.19 \\
3.70\end{array}$ & $\begin{array}{c}6 \\
2 \\
8 \\
13 \\
3 \\
16 \\
0\end{array}$ & $\begin{array}{c}25.00 \\
8.33 \\
33.33 \\
54.17 \\
12.50 \\
66.67 \\
0\end{array}$ & $>0.05$ \\
\hline $\begin{array}{c}\text { Histotype } \\
\text { Serous } \\
\text { Mucinous } \\
\text { Clear Cells } \\
\text { Endometrioid } \\
\text { Transitional } \\
\text { Non-serous }\end{array}$ & $\begin{array}{c}85 \\
2 \\
4 \\
16 \\
0 \\
22\end{array}$ & $\begin{array}{c}79.44 \\
1.87 \\
3.74 \\
14.95 \\
0 \\
20.56\end{array}$ & $\begin{array}{c}25 \\
0 \\
0 \\
1 \\
1 \\
2\end{array}$ & $\begin{array}{c}92.59 \\
0 \\
0 \\
3.70 \\
3.70 \\
7.41\end{array}$ & $\begin{array}{c}19 \\
0 \\
3 \\
2 \\
0 \\
5\end{array}$ & $\begin{array}{c}79.17 \\
0 \\
12.50 \\
8.33 \\
0 \\
20.83\end{array}$ & $>0.05$ \\
\hline $\begin{array}{l}\text { Surgery } \\
\text { No } \\
\text { Upfront } \\
\text { Interval }\end{array}$ & $\begin{array}{l}14 \\
66 \\
10\end{array}$ & $\begin{array}{l}13.08 \\
61.68 \\
9.35\end{array}$ & $\begin{array}{c}1 \\
16 \\
5\end{array}$ & $\begin{array}{c}3.70 \\
59.26 \\
18.52\end{array}$ & $\begin{array}{c}1 \\
19 \\
4\end{array}$ & $\begin{array}{c}4.17 \\
79.17 \\
16.67\end{array}$ & $>0.05$ \\
\hline $\begin{array}{l}\text { Post-neoadjuvant } \\
\text { therapy }\end{array}$ & $\begin{array}{l}10 \\
17\end{array}$ & 15.89 & $\begin{array}{l}5 \\
5\end{array}$ & $\begin{array}{l}18.52 \\
18.52\end{array}$ & $\begin{array}{l}4 \\
0\end{array}$ & $\begin{array}{c}16.67 \\
0\end{array}$ & 0.05 \\
\hline $\begin{array}{l}\text { Residual } \\
\text { yes } \\
\text { no } \\
\text { Unknown }\end{array}$ & $\begin{array}{c}23 \\
70 \\
0\end{array}$ & $\begin{array}{c}24.73 \\
75.26 \\
0\end{array}$ & $\begin{array}{c}5 \\
21 \\
0\end{array}$ & $\begin{array}{c}19.23 \\
80.77 \\
0\end{array}$ & $\begin{array}{c}6 \\
16 \\
1\end{array}$ & $\begin{array}{c}26.09 \\
69.57 \\
4.35\end{array}$ & $>0.05$ \\
\hline $\begin{array}{l}\text { First line therapy } \\
\text { Platinum-based } \\
\text { Non-platinum-based } \\
\text { None }\end{array}$ & $\begin{array}{c}107 \\
0 \\
0\end{array}$ & 100 & $\begin{array}{c}27 \\
0 \\
0\end{array}$ & 100 & $\begin{array}{c}23 \\
0 \\
1\end{array}$ & $\begin{array}{c}95.83 \\
0 \\
4.17\end{array}$ & $>0.05$ \\
\hline
\end{tabular}

${ }^{1}$ from first to third-degree relatives.

Considering only 122 individuals with advanced-stage disease at diagnosis (stage III-IV), after a median follow up of 15 months, median PFS amounted to 15 months in wild-type patients, 38 months in gBRCA carriers, and 24 months in sBRCA mutation carriers (log rank $=0.023$ ) (Figure 2a). Median PFS2 was 23 months in wtBRCA patients, 29 months in gBRCA carriers, and 25 months in sBRCA mutation carriers (log rank $=0.003$ ) (Figure $2 b)$. In this subgroup, two sBRCA (12.5\%) and six gBRCA (26.1\%) mutation carriers received a PARP inhibitor as maintenance after second-line therapy (seven patients received olaparib and one patient niraparib). Finally, median OS was 56 months in wildtype patients, not obtained in gBRCA carriers, and 77 months in sBRCA mutation carriers ( $\log$ rank $=0.026)$ (Figure 2c). In this subgroup as well, sBRCA carriers did not show any advantage in terms of PFS ( $\log$ rank $=0.2$, Figure 2a), PFS2 (log rank $=0.46$, Figure $2 b$ ), and OS (log rank $=0.96$, Figure $2 c$ ) as compared to wild-type patients. Finally, PFS, PFS2, and OS did not significantly differ between s1BRCA and s2BRCA patients (log rank $=0.98$, Figure 2d; log rank $=0.71$, Figure 2e; log rank $=0.96$, Figure 2f). 

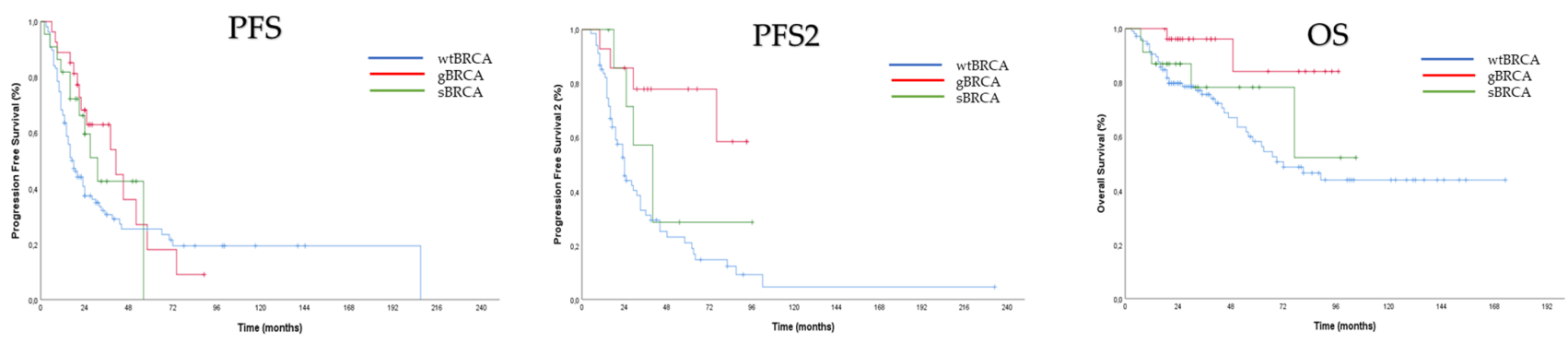

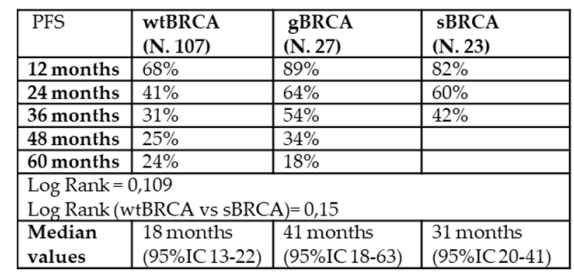

(a)
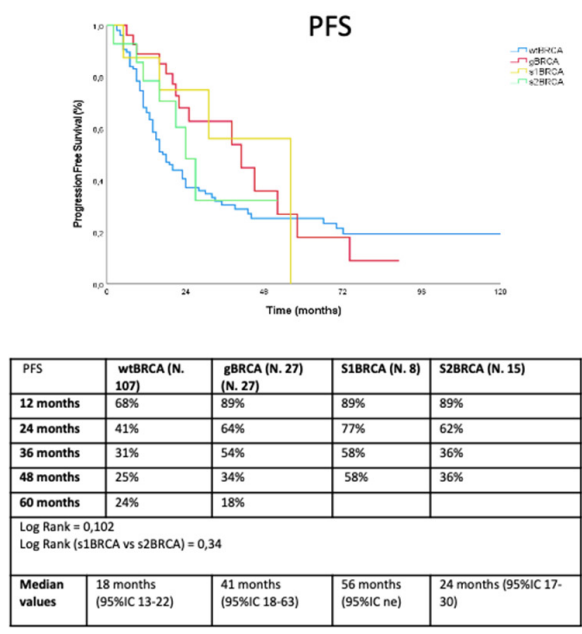

(d)

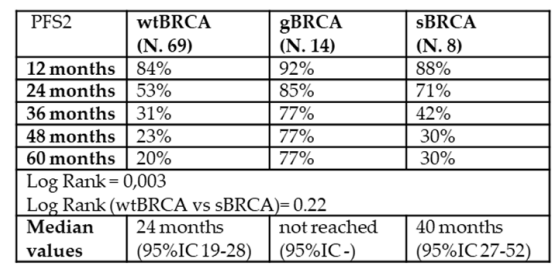

(b)

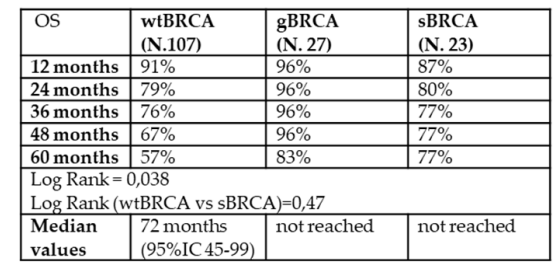

(c)

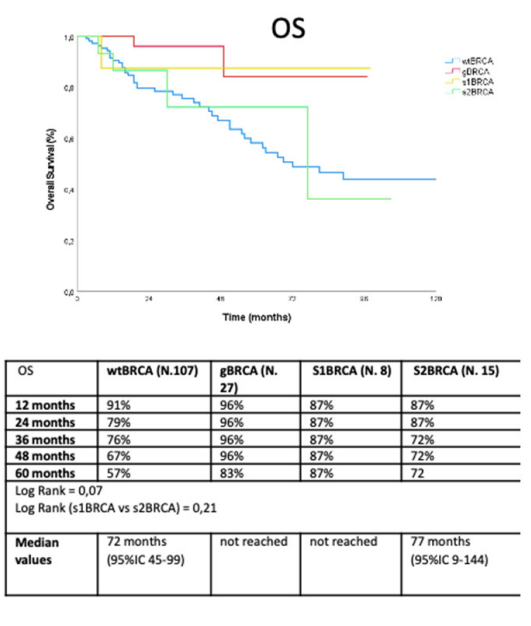

(f)

Figure 1. Outcome analyses of PFS (a,d), PFS2 (b,e), and OS (c,f) according to subgroups in the overall population (blue line for wtBRCA, red line for gBRCA, dark green line for sBRCA, yellow for s1BRCA, and light green line for s2BRCA). PFS: progression-free survival; PFS2: progression free survival 2; OS: overall survival; wtBRCA: wild-type $B R C A$; gBRCA: germline $B R C A$; sBRCA: somatic $B R C A$; s1BRCA: somatic SNVs/indels of $B R C A$; s2BRCA: somatic CNVs of $B R C A$.

In the univariate analysis, several clinical features had a significant negative impact on the OS of wtBRCA patients, including age $\geq 50$ years $(p=0.005)$, stage III-IV $(p=0.04)$, serous histotype $(p=0.03)$, no surgery $(p=0.01)$, and presence of residual disease $(p=0.02)$. Moreover, age $\geq 50$ years $(p=0.001)$, stage III-IV $(p=0.001)$, no surgery $(p=0.001)$, and presence of residual disease $(p=0.01)$ were also predictive of inferior PFS (as shown in Table S1). In the multivariate analysis, FIGO stage, surgery, and residual disease carried significance $(p<0.05)$ for both OS and PFS (Table 3). 

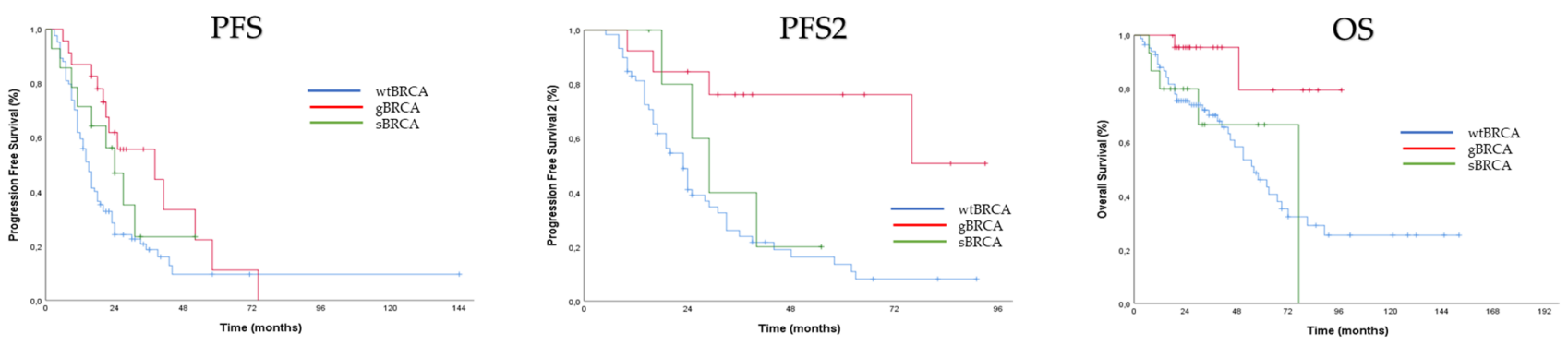

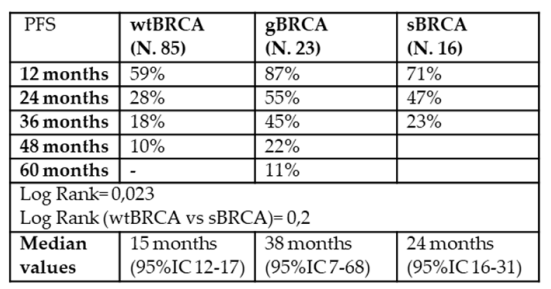

(a)

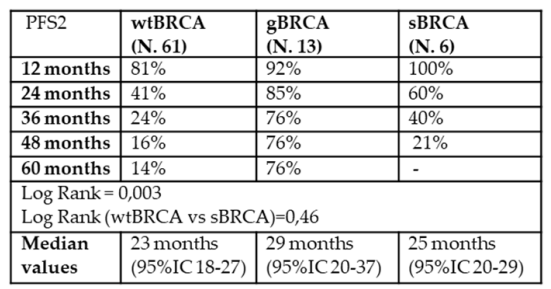

(b)

PFS2
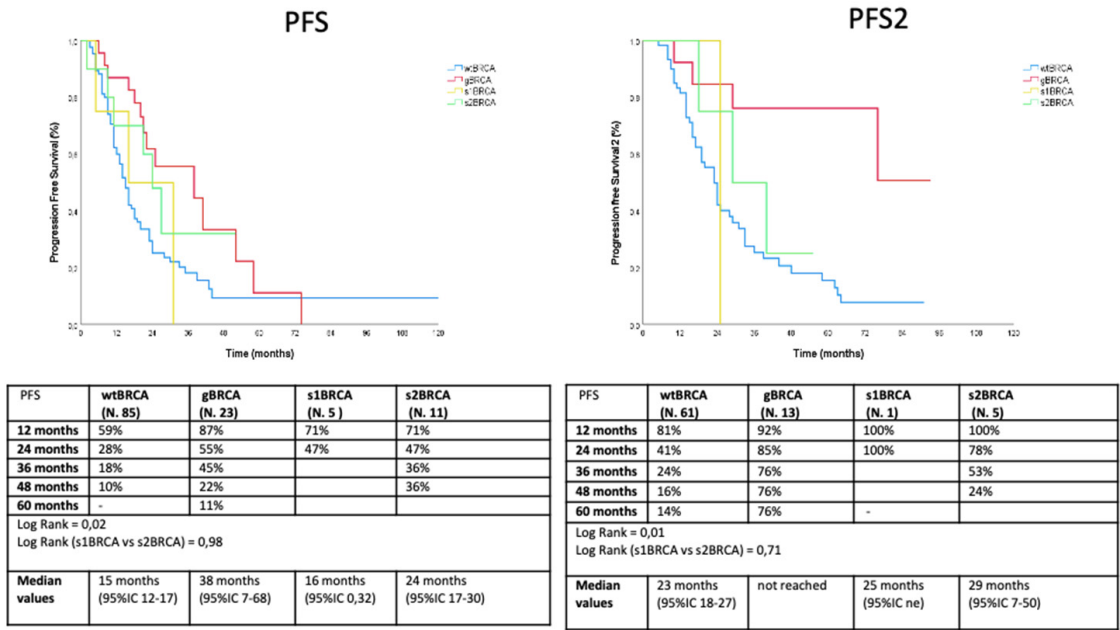

(e)

(d)

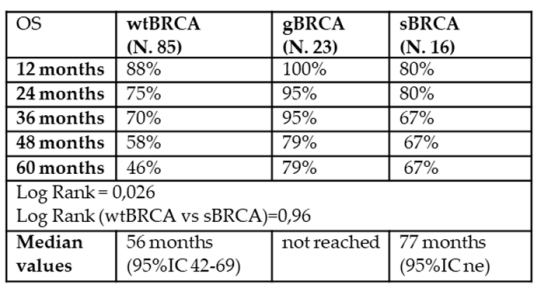

(c)
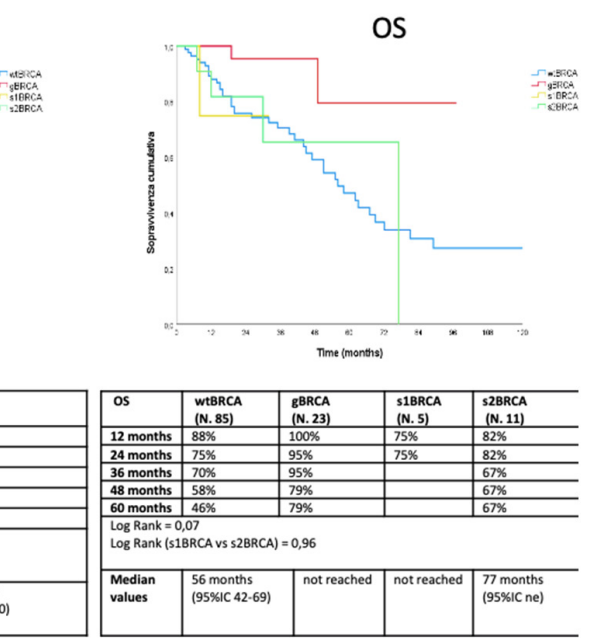

(f)

Figure 2. Outcome analyses of PFS (a,d), PFS2 (b,e), and OS (c,f) according to subgroups of patients diagnosed in advanced stages (blue line for wtBRCA, red line for gBRCA, dark green line for sBRCA, yellow for s1BRCA, and light green line for s2BRCA).

Table 3. Multivariate analysis of indices predicting OS and PFS in wtBRCA. HR: hazard ratio; CI: confidence interval.

\begin{tabular}{cccccc}
\hline & & \multicolumn{2}{c}{ OS } & \multicolumn{2}{c}{ PFS } \\
\cline { 3 - 6 } & & \multicolumn{2}{c}{ wtBRCA } & \multicolumn{2}{c}{ wtBRCA } \\
\hline Factor & Status & HR (95 CI) & $p$-Value & HR (95 CI) & $p$-Value \\
\hline Age & $<50$ & 1.00 & & 1.00 & \\
\hline & $\geq 50$ & 1.02 & 0.9 & 0.24 & 0.83 \\
& & $(0.78-1.56)$ & & $(0.09-1.54)$ & \\
\hline
\end{tabular}


Table 3. Cont.

\begin{tabular}{|c|c|c|c|c|c|}
\hline \multirow[b]{3}{*}{ Factor } & \multirow[b]{3}{*}{ Status } & \multirow{2}{*}{\multicolumn{2}{|c|}{$\begin{array}{c}\text { OS } \\
\text { wtBRCA }\end{array}$}} & \multirow{2}{*}{\multicolumn{2}{|c|}{$\begin{array}{c}\text { PFS } \\
\text { wtBRCA }\end{array}$}} \\
\hline & & & & & \\
\hline & & HR (95 CI) & $p$-Value & HR (95 CI) & $p$-Value \\
\hline \multirow[t]{2}{*}{ FIGO } & $1-2$ & 1.00 & & 1.00 & \\
\hline & $3-4$ & $\begin{array}{c}1.69 \\
(1.18-10.8)\end{array}$ & 0.04 & $\begin{array}{c}0.17 \\
(0.08-0.61)\end{array}$ & 0.05 \\
\hline \multirow[t]{2}{*}{ Serous histotype } & No & 1.00 & & 1.00 & \\
\hline & Yes & $\begin{array}{c}0.35 \\
(0.18-1.01)\end{array}$ & 0.26 & $\begin{array}{c}1.32 \\
(0.21-4)\end{array}$ & 0.42 \\
\hline \multirow[t]{2}{*}{ Surgery } & Yes & 1.00 & & 1.00 & \\
\hline & No & $\begin{array}{c}0.43 \\
(0.07-0.99)\end{array}$ & 0.001 & $\begin{array}{c}1.34 \\
(1.07-1.92)\end{array}$ & 0.003 \\
\hline \multirow[t]{2}{*}{ Residual } & No & 1.00 & & 1.00 & \\
\hline & Yes & $\begin{array}{c}0.31 \\
(0.13-0.77)\end{array}$ & 0.004 & $\begin{array}{c}1.7 \\
(1.02-2.4)\end{array}$ & 0.01 \\
\hline
\end{tabular}

\subsection{Detected BRCA Mutations}

The detected variants in BRCA1 and BRCA2 gene are reported in Table 4.

Table 4. Detected variants in the $B R C A 1$ and $B R C A 2$ gene for each patient. VAF: variant allele frequency; $C N$ : copy number.

\begin{tabular}{|c|c|c|c|c|c|c|}
\hline Patient & $B R C A 1$ & $B R C A 2$ & $\begin{array}{l}\text { VAF in the } \\
\text { Tested Somatic } \\
\text { Sample (\%) }\end{array}$ & $\begin{array}{l}\text { Copy Number (CN) } \\
\text { Call in the Tested } \\
\text { Somatic Sample }\end{array}$ & $\begin{array}{l}\text { Confirmed in } \\
\text { the Matched } \\
\text { Germline } \\
\text { Sample }\end{array}$ & $\begin{array}{l}\text { sBRCA/ } \\
\text { gBRCA }\end{array}$ \\
\hline 1 & / & / & / & $\begin{array}{l}\text { BRCA2DEL entire } \\
\text { gene; } \mathrm{CN}=1\end{array}$ & no & somatic \\
\hline 2 & / & c.993_994delAAinsG,p.(Ile332PhefsX17) & 52.6 & & no & somatic \\
\hline 3 & c. $4675+1 G>A$ & / & 5.4 & & no & somatic \\
\hline 4 & / & / & / & $\begin{array}{c}\text { BRCA1DEL } \\
\text { Exons16-20; CN = } 1\end{array}$ & no & somatic \\
\hline 5 & / & c.8629G >T, p.(Glu2877Ter) & 16 & & no & somatic \\
\hline 6 & / & c.5073dupA, p.(Trp1692Metfs*3) & 8.6 & & no & somatic \\
\hline 7 & / & / & / & $\begin{array}{l}\text { BRCA1DEL entire } \\
\text { gene; } \mathrm{CN}=1\end{array}$ & no & somatic \\
\hline 8 & c.331G>T, p.(Glu111Ter) & / & 50.2 & & no & somatic \\
\hline \multirow{2}{*}{9} & / & / & / & $\begin{array}{l}\text { BRCA1DEL entire } \\
\text { gene; } \mathrm{CN}=1\end{array}$ & no & somatic \\
\hline & $\begin{array}{c}\text { c.2269delG, } \\
\text { p.Val757PhefsX8 }\end{array}$ & / & 59.2 & & no & somatic \\
\hline 10 & / & / & / & $\begin{array}{l}\text { BRCA1DEL entire } \\
\text { gene; } \mathrm{CN}=1\end{array}$ & no & somatic \\
\hline 11 & / & / & / & $\begin{array}{l}\text { BRCA2DEL entire } \\
\text { gene; } \mathrm{CN}=1\end{array}$ & no & somatic \\
\hline \multirow[b]{2}{*}{12} & c. $1687 \mathrm{C}>\mathrm{T}, \mathrm{p} .\left(\mathrm{G} \ln 563^{*}\right)$ & / & 79.5 & & no & somatic \\
\hline & / & I & I & $\begin{array}{l}\text { BRCA2DEL entire } \\
\text { gene; } \mathrm{CN}=1\end{array}$ & no & somatic \\
\hline 13 & / & / & / & $\begin{array}{l}\text { BRCA1DEL entire } \\
\text { gene; } \mathrm{CN}=1\end{array}$ & no & somatic \\
\hline 14 & / & / & / & $\begin{array}{l}\text { BRCA2DEL entire } \\
\text { gene; } \mathrm{CN}=1\end{array}$ & no & somatic \\
\hline 15 & / & / & / & $\begin{array}{l}\text { BRCA2DEL entire } \\
\text { gene; } \mathrm{CN}=1\end{array}$ & no & somatic \\
\hline 16 & / & / & / & $\begin{array}{l}\text { BRCA2DEL entire } \\
\text { gene; } \mathrm{CN}=1\end{array}$ & no & somatic \\
\hline 17 & / & / & / & $\begin{array}{l}\text { BRCA2DEL entire } \\
\text { gene; } \mathrm{CN}=1\end{array}$ & no & somatic \\
\hline 18 & / & / & / & $\begin{array}{l}\text { BRCA2DEL entire } \\
\text { gene; } \mathrm{CN}=1\end{array}$ & no & somatic \\
\hline
\end{tabular}


Table 4. Cont

\begin{tabular}{|c|c|c|c|c|c|c|}
\hline Patient & $B R C A 1$ & $B R C A 2$ & $\begin{array}{l}\text { VAF in the } \\
\text { Tested Somatic } \\
\text { Sample (\%) }\end{array}$ & $\begin{array}{l}\text { Copy Number (CN) } \\
\text { Call in the Tested } \\
\text { Somatic Sample }\end{array}$ & $\begin{array}{l}\text { Confirmed in } \\
\text { the Matched } \\
\text { Germline } \\
\text { Sample }\end{array}$ & $\begin{array}{l}\text { sBRCA/ } \\
\text { gBRCA }\end{array}$ \\
\hline 19 & / & / & / & $\begin{array}{l}\text { BRCA2DEL entire } \\
\text { gene; } \mathrm{CN}=1\end{array}$ & no & somatic \\
\hline 20 & / & / & / & $\begin{array}{l}\text { BRCA2DEL entire } \\
\text { gene; } \mathrm{CN}=1\end{array}$ & no & somatic \\
\hline 21 & / & / & / & $\begin{array}{l}\text { BRCA1DEL entire } \\
\text { gene; } \mathrm{CN}=1\end{array}$ & no & somatic \\
\hline 22 & $\begin{array}{c}\text { c.2670delG, } \\
\text { p.Ser891Profs*2 }\end{array}$ & / & 50.5 & & no & somatic \\
\hline \multirow[b]{2}{*}{23} & / & c.6611delC, p.(Pro2204Leufs*2) & 54.3 & & no & somatic \\
\hline & / & / & / & $\begin{array}{l}\text { BRCA2DEL entire } \\
\text { gene; } \mathrm{CN}=1\end{array}$ & no & somatic \\
\hline 24 & / & / & / & $\begin{array}{l}\text { BRCA1DEL entire } \\
\text { gene; } \mathrm{CN}=1\end{array}$ & no & somatic \\
\hline 25 & $\begin{array}{l}\text { c.3916_3917delTT, } \\
\text { p.Leu1306AspfsX23 }\end{array}$ & / & 78.9 & & yes & germline \\
\hline 26 & / & c.7975A>G, p.(Arg2659Gly) & 80 & & yes & germline \\
\hline 27 & / & c.3847_3848delGT, p.(Val1283LysfsX2) & 85 & & yes & germline \\
\hline 28 & / & c.6037A>T, p.(Lys2013Ter) & 85 & & yes & germline \\
\hline 29 & c. $547+2 \mathrm{~T}>\mathrm{A}$ & / & 83.4 & & yes & germline \\
\hline 30 & $\begin{array}{l}\text { c.2157_2160delAGAA, } \\
\text { p.(Lys719AsnfsX16) }\end{array}$ & / & 92.8 & & yes & germline \\
\hline 31 & c. $4357+1$ delG & / & 90 & & yes & germline \\
\hline 32 & $\begin{array}{c}\text { c.3607C>T, } \\
\text { p.(Arg1203Ter) }\end{array}$ & / & 59,2 & & yes & germline \\
\hline 33 & c. $4096+1 G>A$ & / & 73.4 & & yes & germline \\
\hline 34 & $\begin{array}{c}\text { c.3481_3491delGAAGA } \\
\text { TACTAG, } \\
\text { p.(Glu1161PhefsTer3) }\end{array}$ & / & 91.4 & & yes & germline \\
\hline \multirow{2}{*}{35} & $\begin{array}{l}\text { c.843_846delCTCA, } \\
\text { p.(Ser282TyrX15) }\end{array}$ & / & 83.2 & & yes & germline \\
\hline & / & / & / & $\begin{array}{l}\text { BRCA1DEL entire } \\
\text { gene; } \mathrm{CN}=1\end{array}$ & no & somatic \\
\hline 36 & $\begin{array}{l}\text { c.3288_3289delAA, } \\
\text { p.(Leu1098SerfsX4) }\end{array}$ & / & 94.6 & & yes & germline \\
\hline 37 & $\begin{array}{l}\text { c.5434C>G, } \\
\text { p.(Pro1812Ala) }\end{array}$ & / & 63.8 & & yes & germline \\
\hline 38 & / & c.9097dupA, p.(Thr3033AsnfsX11) & $\begin{array}{l}\text { Tissue not } \\
\text { available }\end{array}$ & & yes & germline \\
\hline 39 & $\begin{array}{c}\text { c.5017 5019delCAC, } \\
\text { p.(His1673del) }\end{array}$ & / & 64.8 & & yes & germline \\
\hline 40 & / & c.5722_5723delCT, p.(Leu1908Argfs*2) & 60.3 & & yes & germline \\
\hline 41 & / & c.7180A $>$ T, p. $\left(\operatorname{Arg} 2394^{*}\right)$ & 78.7 & & yes & germline \\
\hline 42 & $\begin{array}{c}\text { c.3916_3917delTT, } \\
\text { p.(Leu1306Aspfs²3) }\end{array}$ & / & 76 & & yes & germline \\
\hline 43 & c.4508C >A, p.(Ser1503*) & / & 88.6 & & yes & germline \\
\hline 44 & $\begin{array}{c}\text { c.4484G>T, } \\
\text { p.(Arg1495Met) }\end{array}$ & / & 73 & & yes & germline \\
\hline 45 & $\begin{array}{c}\text { c.2157_2160delAGAA, } \\
\text { p.(Lys719Asnfs*16) }\end{array}$ & / & 84.3 & & yes & germline \\
\hline 46 & c.3979C > T, p. $\left(\mathrm{G} \ln 1327^{*}\right)$ & / & 84.6 & & yes & germline \\
\hline 47 & / & c. $9154 \mathrm{C}>\mathrm{T}$, p.(Arg3052Trp) & 59.3 & & yes & germline \\
\hline 48 & / & / & / & $\begin{array}{l}\text { BRCA1DEL } \\
\text { Promotor-Exon2; } \\
\text { CN = } 1\end{array}$ & yes & germline \\
\hline \multirow[b]{2}{*}{49} & / & c.3847_3848delGT, p.(Val1283Lysfs*2) & 77.4 & & yes & germline \\
\hline & / & / & / & $\begin{array}{l}\text { BRCA2DEL entire } \\
\text { gene; } \mathrm{CN}=1\end{array}$ & no & somatic \\
\hline 50 & $\begin{array}{c}\text { c.3916_3917delTT, } \\
\text { p.(Leu1306Aspfs²3) }\end{array}$ & / & 70.2 & & yes & germline \\
\hline 51 & / & c.7558C > T, p. $\left(\operatorname{Arg} 2520^{*}\right)$ & 5.8 & & yes & germline \\
\hline
\end{tabular}

Twenty-four patients were identified as somatic carriers (sBRCA) (patients 1-24) in either BRCA1 (12 patients) or BRCA2 (15 patients). Three patients (number 9, 12, and 23 in 
Table 4) were reported to have two different sBRCA variants. Fifteen patients presented a somatic $\mathrm{CNV}$, and six patients carried likely pathogenic or pathogenic variants, whereas three patients showed both a likely pathogenic or pathogenic variant and a CNV.

Of the $27 \mathrm{gBRCA}$ carriers (patients 25-51), two patients also presented another sBRCA mutation in the analyzed tissue (patients 35 and 49). Overall, 18 gBRCA1 and 9 gBRCA2 mutations were detected. Only one patient presented a CNV, which was detected in the somatic analysis and confirmed by MLPA in the germline counterpart.

If germline and somatic carriers seemed to be equally represented in BRCA-mutated patients (27 gBRCAs vs. $24 \mathrm{sBRCAs}$ ), CNVs seemed to be much more represented in somatic as compared to germline variants ( $20 \mathrm{sCNVs}$ vs. $1 \mathrm{gCNV}$ ). On the other hand, SNVs or indels were more frequently detected as germline variants ( 26 gSNVs vs. 10 sCNVs), as shown in Figure 3.

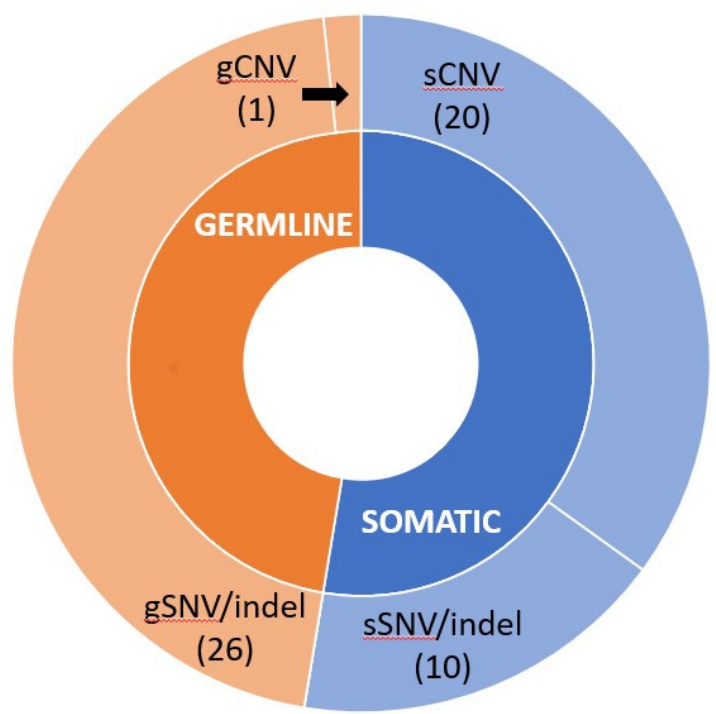

Figure 3. Hierarchical donut chart of likely pathogenic or pathogenic gBRCA and sBRCA variants. The graph shows the origin of mutations found in the inner circle (orange for germline, blue for somatic) and the kinds of variants (CNV or SNV/indel) in the outer circle. Numbers refer to the amount of likely pathogenic or pathogenic variants detected. CNV: copy number variation; SNV: single nucleotide variant.

The variant allele frequency (VAF) for all the likely pathogenic or pathogenic variants in the tissues analyzed was $>50 \%$, except for in three cases. For these, Sanger sequencing and Minor Variant Finder analysis (see Materials and Methods) confirmed the same frequencies found with NGS in the somatic sample and excluded their presence in their germline counterparts. Low variant frequencies in non-constitutive variants may be due to the molecular heterogeneity of the tumor samples.

\section{Discussion}

The prognostic and predictive role of sBRCA mutations is not entirely clarified. Only a few small cohort studies previously showed that, as compared to gBRCA mutations, sBRCA mutations had a similar positive impact on OS and platinum and PARP inhibitor sensitivity $[3,24-26]$. On the other hand, a recent study found no significant impact of sBRCA mutations on PFS or OS [27]. In all these studies, nonetheless, molecular testing of patients did not include $C N V$ analyses of the two BRCA genes. To our knowledge, this is the first study exploring the prognostic and predictive role of sBRCA mutations as compared to gBRCA mutations in patients who were also tested for somatic copy number variations.

The patients were classified according to the presence of sBRCA variants, gBRCA variants, or no pathogenic variants. A total of $17.1 \%$ of the patients carried a pathogenetic gBRCA mutation (66.7\% BRCA1 and $33.3 \%$ BRCA2), while $15.2 \%$ were sBRCA carriers 
(41.7\% BRCA1, 54.2\% BRCA2, and 4.2\% BRCA1+BRCA2). Overall, $81.6 \%$ of the patients included in this study were diagnosed with a serous histotype, since the MFCC started to provide $B R C A$ genetic testing only to patients diagnosed with high-grade serous OC and then to all patients with non-mucinous and non-borderline epithelial OCs. The high rate of serous histotypes could justify the high prevalence of gBRCA mutations detected in our study population. This is in line with data for serous tumors in the literature [2-8]. Besides, the analysis pipeline on these NGS data is able to detect both SNVs and CNVs, leading therefore to an increase in the detection rate of sBRCA mutations and thus explaining the higher rate of sBRCA mutations in this cohort of OC patients. Without CNVs, sBRCA carriers would represent $6.3 \%$, as previously reported in the literature [17-22]. Otherwise, tumors are well known to have increased genomic instability and CNVs [37]. The overrepresentation of somatic CNVs in patients with either BRCA1 or BRCA2 mutations is therefore not surprising. Nevertheless, this finding should be further corroborated in larger series of patients, and an alternative confirmatory method for CNV in the somatic samples should be assessed. For this purpose, it could be interesting to confirm BRCA1 CNVs by using the probe already used for the human epidermal growth factor receptor 2 (HER2) fluorescence in situ hybridization (FISH) test on chromosome 17.

Patients carrying a gBRCA or sBRCA mutation were significantly younger than the wild-type patients. While this finding may not be statistically significant due to the small sample size, gBRCA mutation carriers were predictably more likely to present a family history of BC and/or OC, have a serous histotype, and be in the later stages at diagnosis as compared to the other patients. A higher percentage of gBRCA patients compared to wtBRCA and sBRCA carriers underwent neoadjuvant chemotherapy, possibly due to the higher rate of advanced stage at diagnosis in this group. Most of these gBRCA patients $(80.8 \%)$ had no residual disease after surgery. On these grounds, several ongoing studies on $B R C A$ mutation carriers are evaluating the role of neoadjuvant chemotherapy as compared to up-front surgery in this very chemosensitive subgroup of patients which is frequently diagnosed in the later stages.

Regarding outcomes in the overall population, median PFS did not significantly differ across the three groups, while gBRCA patients showed better PFS2 and OS as compared to sBRCA and wild-type patients. It is likely that the very long PFS of stage I and II OC patients mitigates the biological differences among the three subgroups, whereas the advantages of gBRCA patients emerge in PFS2 and OS after the first relapse, when disease becomes advanced. On the other hand, among women diagnosed in advanced stages (stage III-IV), gBRCA patients showed better PFS, PFS2, and OS compared to all the other patients. The advantage in terms of PFS2 and OS could also be explained by the use of PARP inhibitors as maintenance after the second line of treatment in $26.1 \%$ of gBRCA patients as compared to only $12.5 \%$ of sBRCA patients and none with wtBRCA. Interestingly, in both the overall population and stage III and IV patients, sBRCA did not show any advantage in terms of PFS, PFS2, and OS as compared to wild-type patients. Overall, our results confirm the recent results of You and colleagues [27] and are apparently in contrast with previous works by Lesnock et al. [24] and Hennessy et al. [3]. Furthermore, no significant differences in PFS, PFS2, and OS were observed between SNVs/indels and CNVs, suggesting that these populations are homogeneous in terms of outcome, while they seem to differ from gBRCA patients. Finally, as expected, in the multivariate analyses, advanced FIGO stage, no surgery, and the presence of residual disease in wtBRCA patients were predictive of poorer outcomes.

Our study presents some limitations that should be underlined. First of all, it should be noted that our current data set is not large enough to enable us to definitively determine whether there is a biological difference between sBRCA- and gBRCA/wtBRCA-mutated tumors and, most of all, between SNVs/indel and CNVs. The small sample size likely explains also the lack of significant results in the univariate and multivariate analyses for the sBRCA and gBRCA groups. Secondly, although the FFPE specimens were prepared following the College of American Pathologist Guidelines [33], poor formalin fixation of 
samples and formalin itself might have resulted in fragmented DNA and $\mathrm{C}>\mathrm{U}$ deamination, increasing the risk of false mutated calls. Other limitations are the reliability of existing databases to ascertain pathogenicity in the somatic setting and the temporal and spatial inter- and intra-tumor genetic heterogeneity. In particular, the mutational profile may change over time in the same lesion or may vary in the same individual according to tumor sampling. Indeed, cancer is a dynamic and heterogeneous entity following the principles of clonal evolution, with different areas of the same primary tumor showing different genomic profiles and with metastases acquiring new molecular aberrations as compared to their primary tumors. Additionally, the study lacks gBRCA OC patients undergoing PARP inhibitors as maintenance after first-line therapy and the patients were not evaluated for alterations in other genes involved in the homologous recombination repair system, which could bring survival advantages or platinum/PARP sensitivity like BRCA genes [38] Finally, since the study population included 66 patients diagnosed at least one year before genetic testing, a survival bias should be taken into consideration. Nevertheless, these patients were equally distributed among the three study groups (gBRCA, sBRCA, and wtBRCA), and therefore it is unlikely that this bias could significantly affect the differences in outcome observed.

\section{Conclusions}

In this study the introduction of CNV analyses increased the detection rate of sBRCA mutations, and the resulting classification into gBRCA, sBRCA, and wild-type patients was able to properly stratify OC patient prognosis. In particular, gBRCA mutation carriers presented the best PFS, PFS2, and OS, while sBRCA carriers failed to show any outcome advantage as compared to wild-type patients.

Supplementary Materials: The following are available online at https:/ / www.mdpi.com/2075-441 8/11/3/565/s1, Table S1: Univariate analysis of pre-specified parameters for OS and PFS.

Author Contributions: Conceptualization: A.T., C.P., E.T. (Elena Tenedini) and L.C. (Laura Cortesi); Data curation: A.T., C.P., E.T. (Elena Tenedini) and I.M.; Formal analysis: M.C. and L.M.; Investigation: A.B., E.G., V.T., M.E.F., L.C. (Laura Cortesi), F.G. and S.M.; Methodology: E.B., G.G. and E.T. (Enrico Tagliafico); Supervision: A.T. and L.C. (Luca Cottafavi); Visualization: F.D.; Writing一original draft: A.T. and E.T. (Elena Tenedini); Writing-review and editing: M.V. and L.C. (Laura Cortesi) All authors have read and agreed to the published version of the manuscript.

Funding: The APC was funded by the Angela Serra Association for Cancer Research.

Institutional Review Board Statement: The study was conducted according to the guidelines of the Declaration of Helsinki and was approved by the local Ethical Committee of Modena $\left(n^{\circ} 1373 / 2020\right)$.

Informed Consent Statement: Informed consent was obtained from all subjects involved in the study.

Data Availability Statement: Data are available upon reasonable request.

Conflicts of Interest: The authors declare no conflict of interest.

\section{References}

1. Toss, A.; Molinaro, E.; Sammarini, M.; Del Savio, M.C.; Cortesi, L.; Facchinetti, F.; Grandi, G. Hereditary ovarian cancers: State of the art. Minerva Med. 2019, 110, 301-319. [CrossRef]

2. Alsop, K.; Fereday, S.; Meldrum, C.; DeFazio, A.; Emmanuel, C.; George, J.; Dobrovic, A.; Birrer, M.J.; Webb, P.M.; Stewart, C.; et al. BRCA mutation frequency and patterns of treatment response in BRCA mutation-positive women with ovarian cancer: A report from the Australian Ovarian Cancer Study Group. J. Clin. Oncol. 2012, 30, 2654-2663. [CrossRef]

3. Hennessy, B.T.; Timms, K.M.; Carey, M.S.; Gutin, A.; Meyer, L.A.; Flake, D.D. Somatic mutations in BRCA1 andBRCA2 could expand the number of patients that benefit from poly (ADPribose) polymerase inhibitors in ovarian cancer. J. Clin. Oncol. 2010, 28, 3570-3576. [CrossRef] [PubMed]

4. Jacobi, C.E.; van Ierland, Y.; van Asperen, C.J.; Hallensleben, E.; Devilee, P.; Feluren, G.J.; Kenter, G.G. Prediction of BRCA1/2 mutation status in patients with ovarian cancer from a hospital-based cohort. Genet Med. 2007, 9, 173-179. [CrossRef]

5. Malander, S.; Ridderheim, M.; Masback, A.; Loman, N.; Kristoffersson, U.; Olsson, H.; Nibert, M.; Borg, A. One in 10 ovarian cancer patients carry germ line BRCA1 or BRCA2 mutations: Results of a prospective study in Southern Sweden. Eur. J. Cancer 2004, 40, 422-428. [CrossRef] [PubMed] 
6. Risch, N. The genetic epidemiology of cancer: Interpreting family and twin studies and their implications for molecular genetic approaches. Cancer Epidemiol. Biomarkers Prev. 2001, 10, 733-741.

7. Soegaard, M.; Kjaer, S.K.; Cox, M.; Wozniak, E.; Hogdall, E.; Hogdall, C.; Blaakaer, J.; Jacobs, I.J.; Gayther, S.A.; Ramus, S.J. BRCA1 and BRCA2 mutation prevalence and clinical characteristics of a population-based series of ovarian cancer cases from Denmark. Clin. Cancer Res. 2008, 14, 3761-3767. [CrossRef] [PubMed]

8. Stavropoulou, A.V.; Fostira, F.; Pertesi, M.; Tsitlaidou, M.; Voutsinas, G.E.; Triantafyllidou, O.; Bamias, A.; Dimopoulos, M.A.; Timotheadou, E.; Pectasides, D.; et al. Prevalence of BRCA1 mutations in familial and sporadic Greek ovarian cancer cases. PLoS ONE 2013, 8, e58182. [CrossRef]

9. Ben David, Y.; Chetrit, A.; Hirsh-Yechezkel, G.; Friedman, E.; Beck, B.D.; Beller, U.; Ben-Baruch, G.; Fishman, A.; Levavi, H.; Lubin, F.; et al. Effect of BRCA mutations on the length of survival in epithelial ovarian tumors. J. Clin. Oncol. 2002, 20, 463-466. [CrossRef]

10. Bolton, K.L.; Chenevix-Trench, G.; Goh, C.; Sadetzki, S.; Ramus, S.J.; Karlan, B.Y.; Lambrechts, D.; Despierre, E.; Barrowdale, D.; McGuffog, L.; et al. Association between BRCA1 andBRCA2 mutations and survival in women with invasive epithelial ovarian cancer. JAMA 2012, 307, 382-390. [CrossRef] [PubMed]

11. Boyd, J.; Sonoda, Y.; Federici, M.G.; Bogomolniy, F.; Rhei, E.; Maresco, D.L.; Saigo, P.E.; Almadrones, L.A.; Barakat, P.R.; Brown, C.L.; et al. Clinicopathologic features of BRCA-linked and sporadic ovarian cancer. JAMA 2000, 283, $2260-2265$. [CrossRef] [PubMed]

12. Cass, I.; Baldwin, R.L.; Varkey, T.; Moslehi, R.; Narod, S.A.; Karlan, B.Y. Improved survival in women with BRCA-associated ovarian carcinoma. Cancer 2003, 97, 2187-2195. [CrossRef]

13. Chetrit, A.; Hirsh-Yechezkel, G.; Ben-David, Y.; Lubin, F.; Friedman, E.; Sadetzki, S. Effect of BRCA1/2 mutations on long-term survival of patients with invasive ovarian cancer: The national Israeli study of ovarian cancer. J. Clin. Oncol. 2008, 26, 20-25. [CrossRef] [PubMed]

14. Majdak, E.J.; Debniak, J.; Milczek, T.; Cornelisse, C.J.; Devilee, P.; Emerich, J.; Jassem, J.; De Bock, G.H. Prognostic impact of BRCA1 pathogenic and BRCA1/BRCA2 unclassified variant mutations in patients with ovarian carcinoma. Cancer 2005, 104, 1004-1012. [CrossRef]

15. Yang, D.; Khan, S.; Sun, Y.; Hess, K.; Shmulevich, I.; Sood, A.K.; Zhang, W. Association of BRCA1 and BRCA2 mutations with survival, chemotherapy sensitivity, and gene mutator phenotype in patients with ovarian cancer. JAMA 2011, 306, 1557-1565. [CrossRef] [PubMed]

16. Toss, A.; Cortesi, L. Molecular Mechanisms of PARP Inhibitors in BRCA-related Ovarian Cancer. J. Cancer Sci. Ther. 2013, $5,409-416$.

17. Kurian, A.W.; Kingham, K.E.; Ford, J.M. Next-generation sequencing for hereditary breast and gynecologic cancer risk assessment. Curr. Opin. Obstet. Gynecol. 2015, 27, 23-33. [CrossRef] [PubMed]

18. Axilbund, J.E. Panel testing is not a panacea. J. Clin. Oncol. 2016, 34, 1433-1435. [CrossRef] [PubMed]

19. Cancer Genome Atlas Research Network. Integrated genomic analyses of ovarian carcinoma. Nature 2011, 474, 609-615. [CrossRef] [PubMed]

20. Meyer, L.A.; Anderson, M.E.; Lacour, R.A.; Suri, A.; Daniels, M.S.; Urbauer, D.L.; Nogueras-Gonzalez, G.M.; Scmeler, K.M.; Gershenson, D.M.; Lu, K.H. Evaluating women with ovarian cancer for BRCA1 and BRCA2 mutations: Missed opportunities. Obstet. Gynecol. 2010, 115, 945-952. [CrossRef]

21. Randall, L.M.; Pothuri, B.; Swisher, E.M.; Diaz, J.P.; Buchanan, A.; Witkop, C.T.; Powell, C.B.; Smith, E.B.; Robson, M.E.; Boyd, J.; et al. Multi-disciplinary summit on genetics services for women with gynecologic cancers: A society of gynecologic oncology white paper. Gynecol. Oncol. 2017, 146, 217-224. [CrossRef]

22. Hahnen, E.; Baumann, K.H.; Heimbach, A.; Reuss, A.; Jackisch, C.; Hauke, J.; Park-Simon, T.W.; Richters, L.K.; Hanker, L.C.; Kroeber, S.; et al. Prevalence of somatic mutations in risk genes including BRCA $1 / 2$ in consecutive ovarian cancer patients (AGO-TR-1 study). J. Clin. Oncol. 2016, 34, 5544. [CrossRef]

23. Moschetta, M.; George, A.; Kaye, S.B.; Banerjee, S. BRCA somatic mutations and epigenetic BRCA modifications in serous ovarian cancer. Ann. Oncol. 2016, 27, 1449-1455. [CrossRef]

24. Lesnock, J.; Krivak, T.; Kiet, T.; Sherman, A.; Monk, B.; Ruskin, R.; Kapp, D.; Chen, L.; Chan, J. Germline versus Somatic BRCA mutations: Analysis of the cancer genome atlas project in patients with advanced stage serous epithelial ovarian cancer. Gynecol. Oncol. 2012, 125, S34. [CrossRef]

25. George, A.; Banerjee, S.; Kaye, S. Olaparib and somatic BRCA mutations. Oncotarget 2017, 8, 43598-43599. [CrossRef] [PubMed]

26. Ledermann, J.; Harter, P.; Gourley, C.; Friedlander, M.; Vergote, I.; Rustin, G.; Scott, C.L.; Meier, W.; Shapira-Frommer, R.; Safra, T.; et al. Olaparib maintenance therapy in patients with platinum-sensitive relapsed serous ovarian cancer: A preplanned retrospective analysis of outcomes by BRCA status in a randomised phase 2 trial. Lancet Oncol. 2014, 15, 852-861. [CrossRef]

27. You, Y.; Li, L.; Lu, J.; Wu, H.; Wang, J.; Gao, J.; Wu, M.; Liang, Z. Germline and Somatic BRCA1/2 Mutations in 172 Chinese Women with Epithelial Ovarian Cancer. Front. Oncol. 2020, 10, 295. [CrossRef] [PubMed]

28. Italian Association of Medical Oncology. Raccomandazioni per l'implementazione del test BRCA nelle pazienti con carcinoma ovarico e nei familiari a rischio elevato di neoplasia. V.2-gennaio 2019. Available online: https://www.aiom.it/raccomandazioniper-limplementazione-del-test-brca-nelle-pazienti-con-carcinoma-ovarico-e-nei-familiari-a-rischio-elevato-di-neoplasia / (accessed on 5 October 2020). 
29. Gori, S.; Barberis, M.; Bella, M.A.; Buttitta, F.; Capoluongo, E.; Carrera, P.; Colombo, N.; Cortesi, L.; Genuardi, M.; Gion, M.; et al. Recommendations for the implementation of BRCA testing in ovarian cancer patients and their relatives. Crit. Rev. Oncol. Hematol. 2019, 140, 67-72. [CrossRef]

30. Ledermann, J.; Harter, P.; Gourley, C.; Friedlander, M.; Vergote, I.; Rustin, G.; Scott, C.L.; Meier, W.; Shapira-Frommer, R.; Safra, T.; et al. Olaparib Maintenance Therapy in Platinum-Sensitive Relapsed Ovarian Cancer. N. Engl. J. Med. 2012, 366, 1382-1392. [CrossRef]

31. Kaufman, B.; Shapira-Frommer, R.; Schmutzler, R.K.; Audeh, M.W.; Friedlander, M.; Balmaña, J.; Mitchell, G.; Fried, G.; Stemmer, S.M.; Hubert, A.; et al. Olaparib monotherapy in patients with advanced cancer and a germline BRCA1/2 mutation. J. Clin. Oncol. 2015, 33, 244-250. [CrossRef] [PubMed]

32. Pujade-Lauraine, E.; Ledermann, J.A.; Selle, F.; Gebski, V.; Penson, R.T.; Oza, A.M.; Korach, J.; Huzarski, T.; Poveda, A.; Pignata, S.; et al. Olaparib tablets as maintenance therapy in patients with platinum-sensitive, relapsed ovarian cancer and a BRCA1/2 mutation (SOLO2/ENGOT-Ov21): A double-blind, randomised, placebo-controlled, phase 3 trial. Lancet Oncol. 2017, 18, 1274-1284. [CrossRef]

33. Hammond, M.E.; Hayes, D.F.; Dowsett, M.; Allred, D.C.; Hagerty, K.L.; Badve, S.; Fitzgibbons, P.L.; Francis, G.; Goldstein, N.S.; Hayes, M.; et al. American Society of Clinical Oncology/College Of American Pathologists guideline recommendations for immunohistochemical testing of estrogen and progesterone receptors in breast cancer. J. Clin. Oncol. 2010, 28, 2784-2795. [CrossRef]

34. Wang, K.; Li, M.; Hakonarson, H. ANNOVAR: Functional annotation of genetic variants from high-throughput sequencing data. Nuclei Acids Res. 2010, 38, e164. [CrossRef]

35. McLaren, W.; Pritchard, B.; Rios, D.; Chen, Y.; Flicek, P.; Cunningham, F. Deriving the consequences of genomic variants with the Ensembl API and SNP Effect Predictor. Bioinformatics 2010, 26, 2069-2070. [CrossRef] [PubMed]

36. Richards, S.; Aziz, N.; Bale, S.; Bick, D.; Das, S.; Gastier-Foster, J.; Grody, W.W.; Hegde, M.; Lyon, E.; Spector, E.; et al. Standards and guidelines for the interpretation of sequence variants: A joint consensus recommendation of the American College of Medical Genetics and Genomics and the Association for Molecular Pathology. Genet Med. 2015, 17, 405-424. [CrossRef] [PubMed]

37. Shlien, A.; Malkin, D. Copy number variations and cancer. Genome Med. 2009, 1, 62. [CrossRef]

38. Choi, M.C.; Hwang, S.; Kim, S.; Jung, S.G.; Park, H.; Joo, W.D.; Song, S.H.; Lee, C.; Kim, T.H.; Kang, H.; et al. Clinical Impact of Somatic Variants in Homologous Recombination Repair-Related Genes in Ovarian High-Grade Serous Carcinoma. Cancer Res. Treat 2020, 52, 634-644. [CrossRef] [PubMed] 